\title{
Tablet Formulation and Enhancement of Aqueous Solubility of Efavirenz by Solvent Evaporation Co-Crystal Technique
}

\author{
Vikas G Rajurkar*, Nagare Amit Sunil and Vilas Ghawate
}

MES College of Pharmacy, Savitribai Phule Pune University, Sonai, Ahmednagar, Maharashtra, India

\begin{abstract}
Improvement in the aqueous solubility, physicochemical and micromeritics property of insoluble and slightly soluble drugs is of major concern in pharmaceutical formulations. It is commonly observed in the drug industry that on average more than $35 \%$ of newly discovered drugs are poorly water-soluble. Poor "drug like" properties of lead compounds led to ineffective absorption from the site of administration, less bioavailability which has been designated as an important part of the high clinical failure. In the present work, Efavirenz, nonnucleoside reverse transcriptase inhibitors (NNRTIs) in first-line antiretroviral therapy (ART) belongs to BCS class II drug (highly permeable and low soluble). A simultaneous DSC, FT-IR, SEM, XRPD micro spectroscopy, dissolution study and micromeritics properties studies was used to quickly investigate the co-crystal. Tablet formulation was developed by direct compression method and there evaluation was performed.
\end{abstract}

\section{Keywords: Efavirenz; Co crystal; DSC; SEM; XRPD; FT-IR; Tablet}

\section{Introduction}

Efavirenz is one of the most widely used nonnucleoside reverse transcriptase inhibitors (NNRTIs) in first-line antiretroviral therapy (ART) and is recommended as a preferred option in adult treatment guidelines [1]. It is chemically (4S)-6-chloro-4-(cyclopropylethynyl)1,4-dihydro-4-(trifluoromethyl)-2H-3, 1-benzoxazin-2-one (Figure 1). The bioavailability of orally administrated drugs depends on their absorption from the gastrointestinal (GI) tract; Efavirenz is a poor water soluble BCS class-II drug, with low aqueous solubility of $6.2 \mu \mathrm{g} /$ $\mathrm{mL}$. Due to its high lipophilicity $(\log \mathrm{P}=5.4)$ and consequently poor aqueous solubility, the drug shows relatively low oral absorption and bioavailability (40-45\%) and high inter-subject variability [2]. Efavirenz inhibits the reverse transcriptase enzyme, an essential viral enzyme which transcribes viral RNA into DNA; it acts allosterically by binding to a distinct site away from the active site known as the NNRTI (Non nucleocidal reverse transcriptase inhibitor) pocket [3]. In oral route of administration, poor water soluble drugs present low bioavailability because of their low solubility in GI media. The rate limiting step in the absorption of these drugs is the dissolution rate in the GI fluids rather than their diffusion through the GI membrane [4]. Various methods are available for enhancement of solubility like complexation, co solvents, micro emulsions, micelles, polymeric micelles, liposomes, pharmaceutical salts, pro-drugs, particle size reduction and cocrystalization. The term "crystal engineering" was introduced by R. Pepinsky in 1951. Further G.M.J. Schmidt in the 1960's implemented in the context of topochemical reactions on cinnamic acid. Co crystals

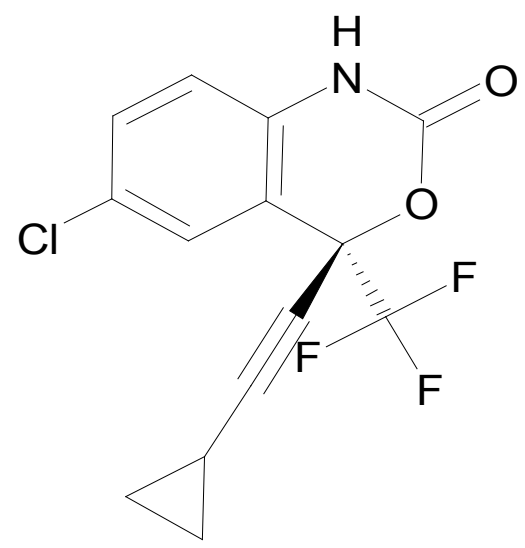

Figure 1: Chemical structure of Efavirenz. are multiple component crystals or crystalline complexes stabilized by types of interaction, including hydrogen bonding, $\mathrm{p}$ stacking, and Vander Waals forces. Different techniques are used for the preparation of co crystals they are as follows: Traditional Techniques 1.Solvent evaporation technique, 2.Solid state grinding or mechanical milling technique and 3.Solvent reduced technique A. Slurring technique and Solvent evaporation technique is commonly used for the preparation of co crystals. In this technique both drug substance and coformers are dissolved in a common solvent and allowed to slow evaporation of a solvent. The technique works on the principle of formation of hydrogen bond in favorable drug substance and complementary coformers $[5,6]$. This process can affect the physical and physicochemical properties. Variation in crystalline habit is one of the proceeding trends in order to increase the solubility, dissolution rate and bioavailability of the poorly soluble drugs. This process could potentially be utilized to a wide range of drugs with different crystalline forms. Different crystals show different dissolution rates and then different biological responses. Pharmaceutical co crystals can improve drug physiochemical and mechanical properties as well as in vivo performance and, hence, are a potential new alternative in the selection of optimal solid dosage forms in product development [7-11]. Coformer's Lactic acid has $2.32 \%$ and Adipic acid have high water solubility.

The present work oriented to improve physicochemical properties of Efavirenz using various conformers i.e., mainly solubility, dissolution and micromeritics properties. Co crystals of Efavirenz with Lactic acid and Adipic acid were prepared in different ratios by solvent evaporation method. The prepared co crystals were subjected to different evaluation tests like solubility analysis, in vitro dissolution study, evaluation of micromeritics properties, particle size determination, XRPD, DSC and SEM. Tablet formulation of Efavirenz co crystals were tried with direct compression method and evaluated.

*Corresponding author: Rajurkar VG, Professor, Quality Assurance Department, MES College of Pharmacy, Sonai-414 105, Taluka-Newasa, District-Ahmednagar, Maharashtra, India, Tel: +919860482926; E-mail: vikas_rajurkar_1973@yahoo.co.in

Received August 02, 2015; Accepted September 01, 2015; Published September 07, 2015

Citation: Rajurkar VG, Sunil NA, Ghawate V (2015) Tablet Formulation and Enhancement of Aqueous Solubility of Efavirenz by Solvent Evaporation CoCrystal Technique. Med chem S2:002. doi: 10.4172/2161-0444.1000002

Copyright: (c) 2015 Rajurkar VG, et al. This is an open-access article distributed under the terms of the Creative Commons Attribution License, which permits unrestricted use, distribution, and reproduction in any medium, provided the original author and source are credited. 


\section{Materials and Methods}

\section{Synthesis of co-crystals}

Method like solvent evaporation co-crystallization was employed for the synthesis of co crystals of Lactic acid and Adipic acid with Efavirenz. Solvent evaporation method was found to be the suitable for the synthesis of co-crystals in the present study.

\section{Methods of synthesis}

\section{Solvent evaporation method}

Co-crystals of Efavirenz with Lactic acid and Adipic acid: The cocrystals of Efavirenz were prepared by co-former method. Equimolar or different molar quantities of Efavirenz and different co-formers such as Lactic and Adipic acid were dissolved in $20 \mathrm{ml}$ ethanol by keeping in water bath maintained at a temperature at $80^{\circ} \mathrm{C}$ to obtain clear solution. The solution was allowed to cool in ice bath for about 5 $\mathrm{hr}$ for thorough crystallization to occur. The crystals were collected by filtration through a Whatmann filter paper, dried in air for $24 \mathrm{hr}$ and finally stored in desiccators until further investigated by microscopic, melting point, SEM, XRPD and DSC study $[12,13]$.

\section{Characterization}

The prepared co-crystals and its tablets were investigated by different techniques and analysis which include:

\section{Melting Point (Veego, Mumbai)}

2. Solubility of Efavirenz and co crystals with Lactic acid and Adipic acid

\section{Microscopic evaluation (Motic, BA-210, Hong Kong)}

4. Differential Scanning Calorimetry (Detector 60, Mettler-Toledo DSC 821e, USA)
5. X-ray Powder Diffraction (PW 1729, Philips, Netherland)
6. SEM (JSM 6360 LV, Joel, Japan)
7. FT-IR (Alpha-E Bruker, Germany)
8. Weight Variation
9. Friability Test Data
10. Hardness and Thickness Test
11. Disintegration and
12. Dissolution study

\section{Microscopic evaluation}

Microscopic evaluation was observed under Motic BA 210 microscope, which was used as a primary investigation tool to confirm the formation of co-crystals visually and to observe the crystal habit of the prepared co-crystals, compared the shape of co-crystals was with the pure drug. Crystallization of the pure drug was also carried out in the same solvent which was used for the synthesis of co-crystals to investigate differences in crystal habit of co-crystals with that of pure drugs.

\section{Solubility of Efavirenz and its Co crystals with Lactic acid and} Adipic acid

The solubility study was carried out first in distill water at $27^{\circ} \mathrm{C}$; excess amount of Efavirenz or its co crystals was added in $10 \mathrm{~mL}$ distill water and the bottle was screw capped with stopper. The bottle was kept shaking for about $24 \mathrm{hr}$ and then centrifuge for $15 \mathrm{~min}$; filtered; filtrate $1.2 \mathrm{~mL}$ diluted up to $10 \mathrm{~mL}$ with aqueous ethanol i.e., ethanol and water (6:4) ratio; finally the absorbance of sample was taken at $247.8 \mathrm{~nm}$ (Table 1)[14].

\section{Differential Scanning Calorimetric (DSC)}

DSC analysis is a thermo analytical technique used to identify the difference in the amount of heat required to increase the temperature of a sample and reference as a function of temperature. The samples were analyzed by Differential Scanning Calorimeter (Detector 60, Mettler-Toledo DSC 821e) over the range of $0-200^{\circ} \mathrm{C}$ at the rate of $10^{\circ} \mathrm{C}$ per minute. DSC, thermo analysis gave characteristic and comparable results for the APIs and the synthesized co-crystals as shown in Figure $2 \mathrm{~A}$ and $2 \mathrm{~B}[15]$.

\section{X-ray Powder Diffraction (XRPD)}

X-ray Powder Diffraction was done for the prepared co-crystals; it reveals the information about the crystal structure, chemical composition, and physical properties of the material and also helps in structural characterization. XRPD spectra on a sample stage PW 1729, Philips, Netherland were performed on samples of $05-10 \mathrm{mg}$ in the range of -100 to $200^{\circ} \mathrm{C}$ at a heating rate of $10^{\circ} \mathrm{C} / \mathrm{min}\left(\mathrm{N}_{2}\right.$-atmosphere: $80 \mathrm{l} / \mathrm{min}$ ) at the minimum step size 02 Theta: 0.001 and minimum step size Omega: 0.001 (Figure 3A-3C).

\section{Scanning Electron Microscopy (SEM)}

The surface characteristic of prepared crystal was studied by SEM (JSM 6360 LV, Joel, Japan). Powder samples was mounted onto aluminum stub using double sided adhesive tape and sputter coated with a thin layer of gold at 10 Torr vacuum before examination. The specimens were scanned with an electron beam of acceleration potential of $20 \mathrm{kV}$ and the images were collected as secondary electron mode. SEM analysis has been performed for the pure drug and cocrystals (Figure 4A-4C).

\section{Fourier Transform Infrared (FT-IR)}

Fourier Transform Infrared (FT-IR) spectra were recorded for the Efavirenz, co-former (Lactic acid and Adipic acid) and co-crystals. The spectra were recorded in an Alpha-E Bruker FT-IR spectrophotometer. Potassium bromide pellet method was employed and background spectrum was collected under identical conditions. Each spectrum was derived from 16 single average scans collected in the range of 400-4000 $\mathrm{cm}^{-1}$ at the spectral resolution of $02 \mathrm{~cm}^{-1}$; (Figure 5A and 5B) [16-18].

Study of micromeritrics properties of Efavirenz and its cocrystals

Angle of repose of Efavirenz, its co-crystal with Lactic acid and Adipic acid: The frictional force in powder can be measured by the angle of repose. It is the maximum angle possible between the surface

\begin{tabular}{|c|c|}
\hline Compound & Solubility \\
\hline Efavirenz & $5.46 \mu \mathrm{g} / \mathrm{mL}$ \\
\hline Efavirenz co-crystal with Lactic acid (1:1) & $9.25 \mu \mathrm{g} / \mathrm{mL}$ \\
\hline Efavirenz co-crystal with Lactic acid (1:2) & $11.91 \mu \mathrm{g} / \mathrm{mL}$ \\
\hline Efavirenz co-crystal with Lactic acid (1:3) & $12.94 \mu \mathrm{g} / \mathrm{mL}$ \\
\hline Efavirenz co-crystal with Lactic acid (1:4) & $14.04 \mu \mathrm{g} / \mathrm{mL}$ \\
\hline Efavirenz co-crystal with Lactic acid (1:5) & $\mathbf{1 5 . 0 1} \boldsymbol{\mu g} / \mathrm{mL}$ \\
\hline Efavirenz co-crystal with Adipic acid (1:1) & $7.84 \mu \mathrm{g} / \mathrm{mL}$ \\
\hline Efavirenz co-crystal with Adipic acid (1:2) & $11.19 \mu \mathrm{g} / \mathrm{mL}$ \\
\hline Efavirenz co-crystal with Adipic acid (1:3) & $11.48 \mu \mathrm{g} / \mathrm{mL}$ \\
\hline Efavirenz co-crystal with Adipic acid (1:4) & $15.74 \mu \mathrm{g} / \mathrm{mL}$ \\
\hline Efavirenz co-crystal with Adipic acid (1:5) & $\mathbf{1 8 . 3 1 ~} \mathbf{\mu g} / \mathrm{mL}$ \\
\hline
\end{tabular}

Table 1: Solubility of Efavirenz and its Co crystals with Lactic acid and Adipic acid. 


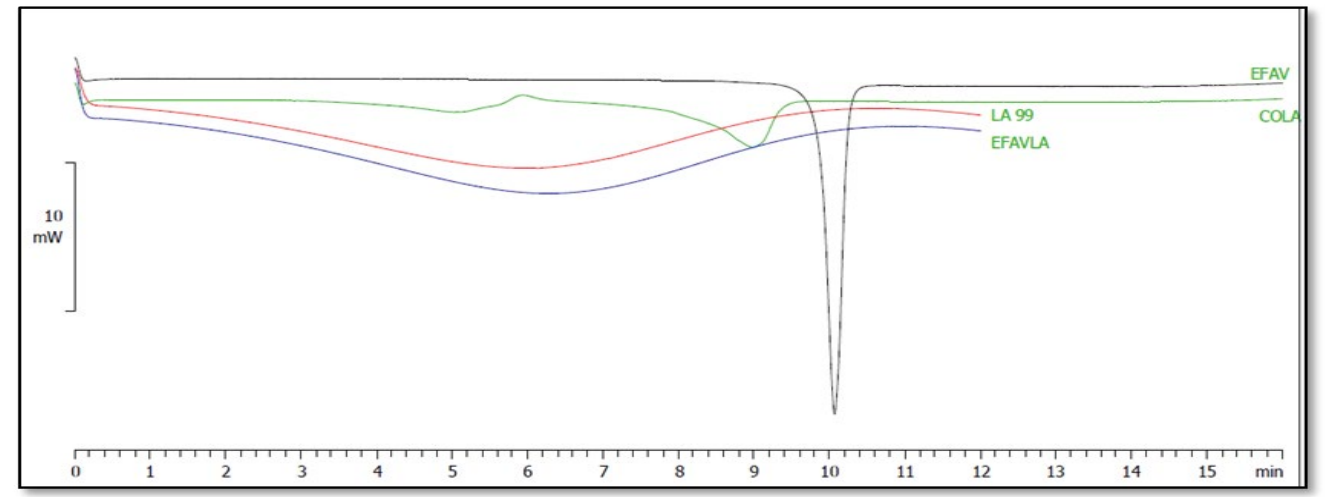

$\mathbf{A}$

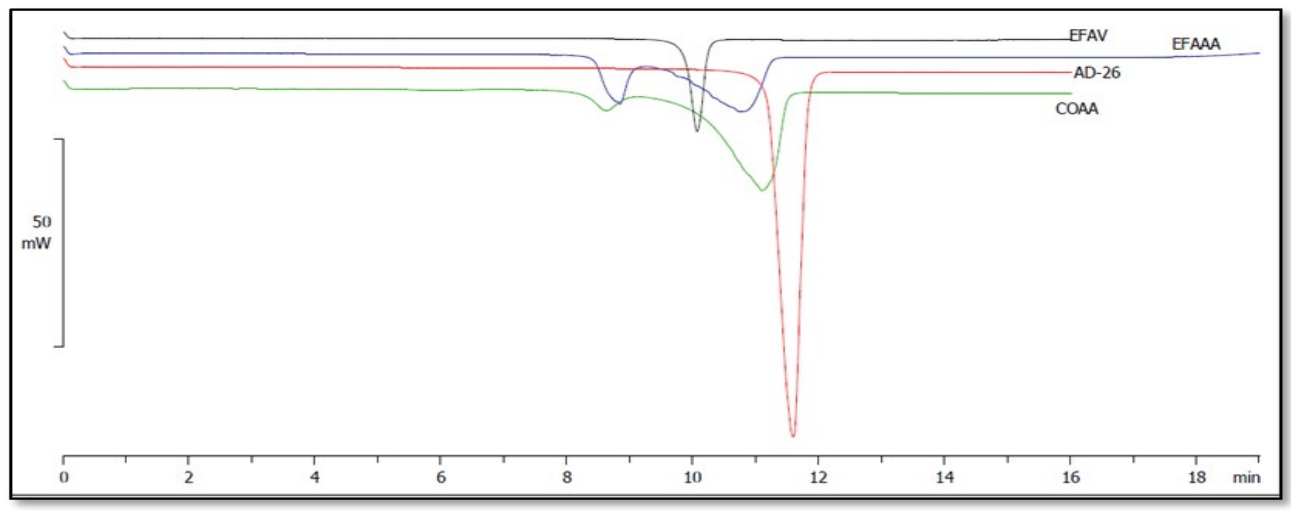

B

Figure 2: (A) DSC overlay spectra of Efavirenz-EFAV, Lactic acid-LA 99, physical mixture of Lactic acid and formulation of Efavirenz co-crystal with Lactic acid co-former-COLA (1:5). (B) DSC overlay spectra of Efavirenz-EFAV, Adipic acid-AD 26, physical mixture of Adipic acid and Efavirenz-EFAAA and formulation of Efavirenz co-crystal with Adipic acid co-former-COAA (1:5).

of pile of powder and the horizontal plane. The blend that has angle of repose in between $20^{\circ}-30^{\circ}$ is best for compression as it has good flow property. Angle of repose was calculated by fixed funnel method, in which funnel was fixed to a stand in such a way that the lower tip of funnel was $2.5 \mathrm{~cm}$ above the surface. A graph paper was placed on the flat surface. The blend was allowed to fall freely on the graph paper through the funnel, till the tip of heap formed just touched the funnel. The radius of heap was noted and from this angle of repose was determined using following (Table 2).

$\theta=\tan ^{-1}(\mathrm{~h} / \mathrm{r})-----01$

Where, $\mathrm{h}=$ height of pile; $\mathrm{r}=$ radius of pile

\section{Bulk density and Tapped density}

Bulk density was determined by pouring preweighed and presieved bulk drug into a graduated cylinder via a large funnel and the volume was measured and recorded as bulk volume. The cylinder was tapped until powder bed volume reached a minimum volume and the volume was recorded as tapped volume. The bulk density and tapped density were calculated using following.

Bulk density=Mass/Bulk volume; Tapped density=Mass/Tapped volume ---- 02

\section{Hausner's Ratio}

Hausner's found that the ratio of tapped density/bulk density was related to inter particle friction as such, and could be used to predict powder flow properties. He showed that the powder with low inter particle friction had ratio of approximately 1.2, whereas more cohesive less free flowing powders have Hausner's ratio greater than 1.6. Hausner's ratio less than 1.25 indicates good flow. It is the ratio of tapped density to the bulk density.

Hausner's ratio=Tapped density/Bulk density ------ 03

\section{Carr's index}

This property is also known as percent compressibility, indirectly related to the flow rate, cohesiveness and particle size. Compressibility is the ability of powder to decrease in volume under pressure, is obtained from density determinations. The compressibility index of the powder was determined by Carr's compressibility index. It is simple, fast and accurate method of predicting powder flow characteristics (Table 3).

Carr's Index of Efavirenz

Carr's Index=Tapped Density-Bulk Density $\times 100$------ 04

Carr's index is the measure of the potential strength that the powder could build up in its arch in a hopper and also the ease with which such an arch could be broken.

\section{Preparation of Tablet by Direct Compression}

Accurately measured quantities of drug and excipients were 


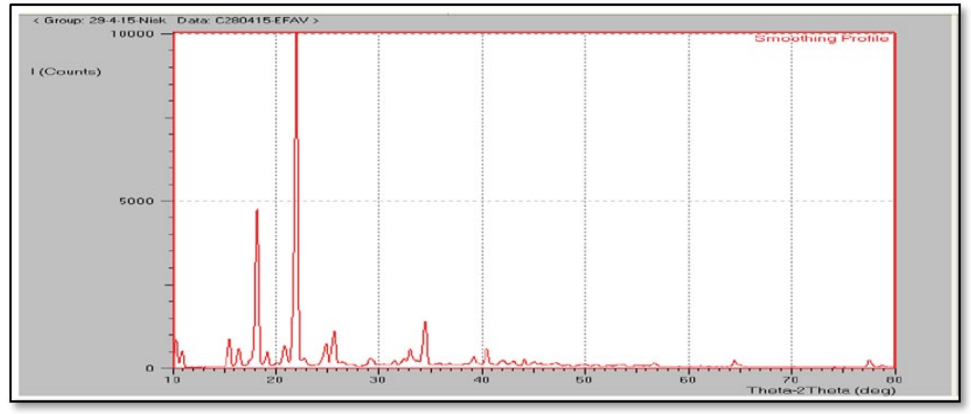

$\mathbf{A}$

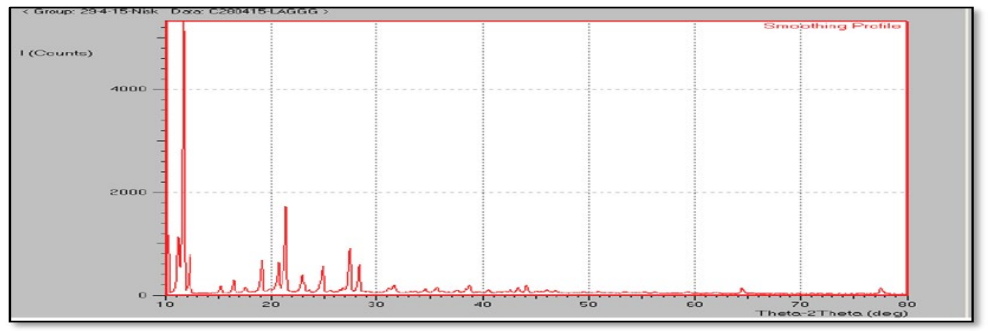

B

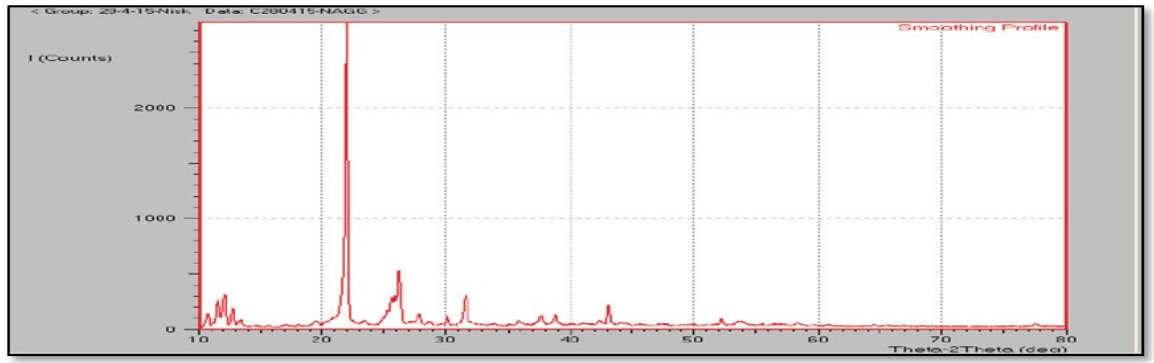

C

Figure 3: XRPD spectra of (A) Efavirenz, (B) Co-crystals of Efavirenz with Lactic acid and (C) Co-crystals of Efavirenz with Adipic acid.

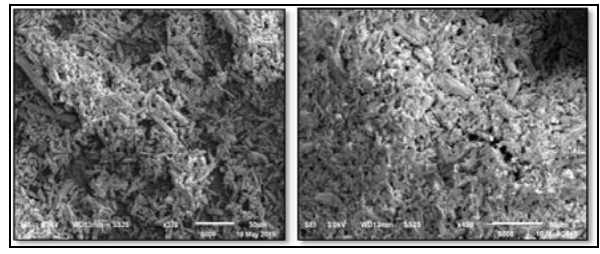

A

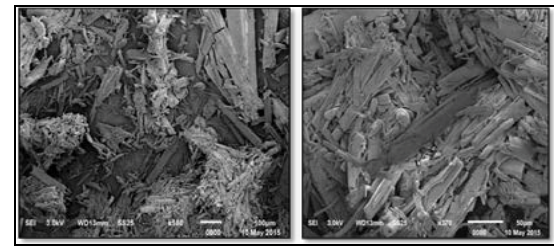

B

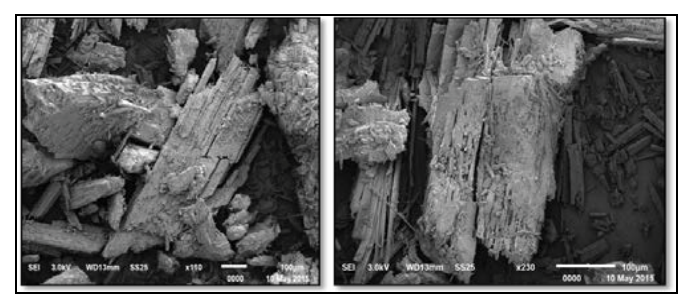

C

Figure 4: SEM images for (A) Efavirenz, (B) Co-crystals of Efavirenz with Lactic acid and (C) Efavirenz with Adipic acid. 

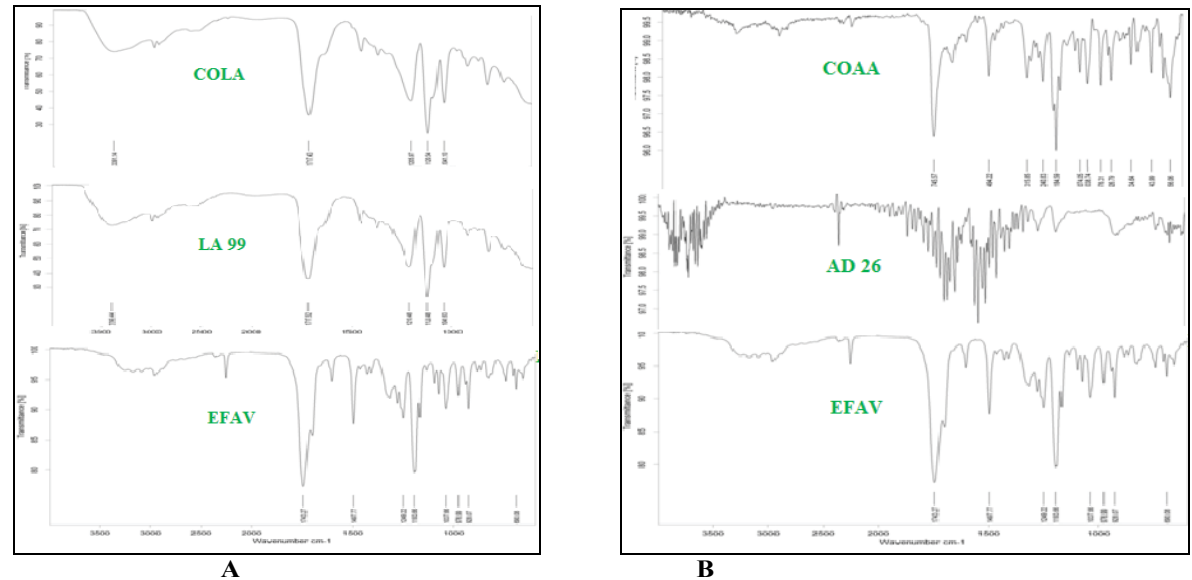

Figure 5: FT-IR spectra for (A) Efavirenz-EFAV, Lactic acid-LA 99 and formulation of Efavirenz co-crystal with Lactic acid co-former-COLA (1:5), (B) Efavirenz-EFAV, Adipic acid-AD 26 and formulation of Efavirenz co-crystal with Adipic acid co-former-COAA (1:5).

\begin{tabular}{|c|c|c|c|}
\hline Parameter & Efavirenz & \multicolumn{2}{|c|}{ Co crystal with } \\
\hline $\mathrm{h}$ & & Lactic acid (1:5) & Adipic acid (1:5) \\
\hline $\mathrm{r}$ & $2.3 \mathrm{~cm}$ & $1.3 \mathrm{~cm}$ & $1.9 \mathrm{~cm}$ \\
\hline $\tan \varnothing^{-1}$ & $2.9 \mathrm{~cm}$ & $4.9 \mathrm{~cm}$ & $3.6 \mathrm{~cm}$ \\
\hline Type of flow & 38.41 & 14.85 & 27.82 \\
\hline & Very Poor & Good & Good \\
\hline
\end{tabular}

Table 2: Angle of repose of Efavirenz, its co-crystal with Lactic acid and Adipic acid.

\begin{tabular}{|c|c|c|c|}
\hline \multirow[t]{2}{*}{ Parameter } & \multirow[t]{2}{*}{ Efavirenz } & \multicolumn{2}{|c|}{ Efavirenz Co crystal with } \\
\hline & & Lactic acid (1:5) & Adipic acid (1:5) \\
\hline Mass & $10 \mathrm{~g}$ & $4.17 \mathrm{~g}$ & $4.17 \mathrm{~g}$ \\
\hline Bulk volume & $38 \mathrm{cc}$ & $12 \mathrm{cc}$ & $13 \mathrm{cc}$ \\
\hline Bulk density & $0.26 \mathrm{~g} / \mathrm{cc}$ & $0.34 \mathrm{~g} / \mathrm{cc}$ & $0.32 \mathrm{~g} / \mathrm{cc}$ \\
\hline Tapped volume & $20 \mathrm{cc}$ & $10 \mathrm{cc}$ & $11 \mathrm{cc}$ \\
\hline Tapped density & $0.50 \mathrm{~g} / \mathrm{cc}$ & $0.41 \mathrm{~g} / \mathrm{cc}$ & $0.37 \mathrm{~g} / \mathrm{cc}$ \\
\hline Hausner's Ratio & 1.92 & 1.2 & 1.15 \\
\hline Carr's index & $24 \%$ & $7 \%$ & $5 \%$ \\
\hline$\%$ Compr & 12 to $16: \mathrm{G}$ & Poor; 35 to $38:$ Ve & nely poor \\
\hline
\end{tabular}

Table 3: Bulk density, Tapped density, Carr's index and Hausner's ratio of Efavirenz, its co-crystal with Lactic acid and Adipic acid.

taken as shown in Table 4. In this method involves simple blending of active pharmaceutical ingredient (API) with other Ingredients and direct compaction of the resultant mixture passed through $40 \#$ and were taken in to ' $\mathrm{v}$ ' cone blender and blend for $15 \mathrm{~min}$ and taken for compression. The tablets were punched using rotary compression machine (Cadmac) of $12 \mathrm{~mm}$ punch. These compressed tablets were transferred in to packing area and these tablets were packed in paperAluminum packing with LDP coating.

\section{Evaluation of Tablets}

All the tablets were evaluated for different parameters as thickness, hardness, friability, uniformity of weight, disintegration time, in vitro dissolution and drug content study [19].

\section{Dimensional analysis}

The thickness and diameter of tablets was determined using vernier caliper. Twenty tablets from each batch were used and average values were calculated (Table 5).

\section{Hardness}

The Monsanto hardness tester was used to determine the tablet hardness. The tablet was held between affixed and moving jaw. Scale was adjusted to zero; load was gradually increased until the tablet fractured. The value of the load at that point gives a measure of the hardness of the tablet. It is expressed in $\mathrm{kg} / \mathrm{cm}^{2}$. For each formulation, the hardness of six tablets was determined and average value was calculated (Table 5).

\section{Weight variation}

Randomly selected twenty tablets were weighed individually and together in a single pan balance. The average weight was noted and standard deviation calculated. The tablets pass the test if not more than two tablets fall outside the percentage limit and none of the tablet differs by more than double percentage limit (Table 5). IP limit for weight variation in case of tablets weighting up to $120 \mathrm{mg}$ is $\pm 10 \%, 120$ $\mathrm{mg}$ to $300 \mathrm{mg}$ is $\pm 7.5 \%$ and more than $300 \mathrm{mg}$ is $\pm 5 \%$.

$\mathrm{PD}=\left[\left(\mathrm{W}_{\text {avg }}-\mathrm{W}_{\text {initial }}\right) /\left(\mathrm{W}_{\text {avg }}\right)\right] \times 100$

Where, $\mathrm{PD}=$ Percentage deviation; $\mathrm{W}_{\text {avg }}=$ Average weight of tablet, $\mathrm{W}_{\text {initial }}=$ Individual weight of tablet.

\section{Friability}

Twenty tablets samples were weighed accurately and placed in 


\begin{tabular}{|c|c|c|}
\hline Ingredient & & Quantity/Tablet \\
\hline Co- crystal of Lactic acid & $522.37 \mathrm{mg}$ & $-16.79 \mathrm{mg}$ \\
\hline Co- crystal of Adipic acid & ---- & $125 \mathrm{mg}$ \\
\hline Sucrose & $07 \mathrm{mg}$ & $26.81 \mathrm{mg}$ \\
\hline Polyvinyl alcohol & $4.22 \mathrm{mg}$ & \\
\hline
\end{tabular}

Table 4: Formula for Efavirenz Co-crystal Tablet (With Lactic Acid Co-former (1:5) and Adipic acid co-former (1:5)).

\begin{tabular}{|c|c|c|c|}
\hline \multirow{2}{*}{ Test } & \multicolumn{2}{|c|}{ Efavirenz Co crystal with } & \multirow{2}{*}{ Observation } \\
\cline { 2 - 3 } & Lactic acid (1:5) & Adipic acid (1:5) & \multirow{2}{*}{ Complies with I.P } \\
\hline Thickness & $3.05 \pm 0.03 \mathrm{~mm}$ & $3.07 \pm 0.02 \mathrm{~mm}$ & Complies with I.P \\
\hline Hardness & $3.3 \pm 0.01 \mathrm{~kg}$ & $4.05 \pm 0.03 \mathrm{~kg}$ & Complies with I.P \\
\hline Wt. Variation & $510.1-545.7 \mathrm{mg}$ & $690.5-652.4 \mathrm{mg}$ & Complies with I.P \\
\hline Friability & $0.79 \pm 0.09 \%$ & $0.63 \pm 0.04 \%$ & Complies with I.P \\
\hline Disintegration & $7 \pm 0.16 \mathrm{~min}$ & $8 \pm 0.08 \mathrm{~min}$ & \\
\hline
\end{tabular}

Table 5: Evaluation of post direct compressed Efavirenz co crystal tablets.

friabilator (Roche friabilator). After the given specification (4 min at $25 \mathrm{rpm}$ ), loose dust was removed from the tablets. Finally tablets were weighed. The loss in weight indicates the ability of the tablets to withstand this type of wear (Table 5).

$\%$ friability was then calculated by $=\left[\left(\mathrm{W}_{\text {avg }}-\mathrm{W}_{\text {initial }}\right) /\left(\mathrm{W}_{\text {avg }}\right)\right] \times 100$

\section{Disintegration test}

Disintegration is evaluated to ensure that the drug substance is fully available for dissolution and absorption from the gastrointestinal tract. Disintegration test was carried out using tablet disintegration test apparatus (Electro lab, India) using distilled water without disk at room temperature $\left(37 \pm 2^{\circ} \mathrm{C}\right)$ (Table 5).

\section{In vitro dissolution study}

UV-VIS measurement: The samples were analyzed UV spectrophotometeter and the absorbance was recorded at $252 \mathrm{~nm}$ using UV spectrophotometer against a dissolution medium as a blank. In vitro dissolution study of co-crystal offers a convenient and inexpensive means of predicting absorption and bioavailability of formulations of the same drug. The release profile of co crystal of Efavirenz with Lactic Acid or Adipic acid or tablet of co crystal of Efavirenz with Lactic Acid or Adipic acid predicts how a delivery system might function and gives valuable insight into its in vivo behavior. In vitro release profile for co crystals or tablet as well as pure drug was performed using USP XXIV type II (paddle) dissolution apparatus. Took co crystal sample equivalent to $200 \mathrm{mg}$ of Efavirenz or $200 \mathrm{mg}$ equivalent Efavirenz co crystal tablet was added to $1000 \mathrm{ml}$ phosphate buffer $\mathrm{pH} 7.2$ at $37 \pm$ $0.5^{\circ} \mathrm{C}$ and stirred at $75 \mathrm{rpm}$. Aliquot of $5 \mathrm{ml}$ was withdrawn at time intervals of $5,10,15,30$ and $45 \mathrm{~min}$. The withdrawn volume was replaced with the same volume of dissolution medium in order to keep the total volume constant [14-20]. The absorbance of the samples was measured at $\lambda \max 252 \mathrm{~nm}$ (Tables 6 and 7; Figures 6 and 7).

\section{Drug Content}

Co-crystals of Efavirenz with Lactic acid or Adipic acid $10 \mathrm{mg}$ was accurately weighed and transferred to volumetric flask $(10 \mathrm{~mL})$. It was dissolved properly in ethanol and diluted up to the mark with ethanol to obtain final concentration of $1000 \mu \mathrm{g} / \mathrm{mL}$ and used as a stock solution (Stock Solution I). One $\mathrm{ml}$ of stock solution I was withdrawn and further diluted by ethanol to give $10 \mu \mathrm{g} / \mathrm{mL}$. This solution was scanned in the UV region of $400-190 \mathrm{~nm}$. The spectrum was obtained to determine the maximum absorbance $(\lambda \max )$. They were analyzed by UV Visible spectrophotometer by measuring the absorbance at $247.8 \mathrm{~nm}$ (Table 8 ).

\section{$\mathrm{y}=\mathrm{mx}+\mathrm{c}$}

Where, $\mathrm{y}=$ Absorbance, $\mathrm{m}=$ Slope, $\mathrm{c}=$ Intercept

\section{Results and Discussion}

Synthesis of co-crystals of Efavirenz with Lactic acid or Adipic acid was carried out by solvent evaporation method and its tablet were produced by direct compression method. Ethanol employed as solvents for the synthesis of co-crystals was proved to be the suitable for formation of co crystals. Other solvents were used but they were failed to produce the crystal pattern of co-crystals different from the crystals pattern of pure drugs when observed using microscopy. Microscopic analysis of prepared co-crystals revealed visual difference between the co-crystals and pure drug Efavirenz. In aqueous solubility study of Efavirenz and its co crystals result reveal that Efavirenz 5.46 $\mu \mathrm{g} / \mathrm{mL}$, Efavirenz co-crystal with Lactic acid (1:5)15.01 $\mu \mathrm{g} / \mathrm{mL}$ and Efavirenz co-crystal with Adipic acid (1:5): $18.31 \mu \mathrm{g} / \mathrm{mL}$, which suggest 3-3.5 fold improvement in solubility of co crystals than pure drug as shown in Table 1. The Differential Scanning Calorimetry (DSC) data of synthesized co crystals A (Efavirenz with Lactic acid) and B (Efavirenz with Adipic acid) showed difference of melting point which confirms the formation of stable co-crystals. The DSC of synthesized co crystals A (Efavirenz with Lactic acid) shows the single prominent endothermic peak at $129.67^{\circ} \mathrm{C}$ as shown in Figure 2A, which is neither the melting point of Efavirenz nor boiling point of Lactic acid. This supports the formation of co-crystals of Efavirenz with Lactic acid. Similarly, DSC result of $\mathrm{B}$ shows the prominent endothermic peak at $149.76^{\circ} \mathrm{C}$ as shown in Figure 2B, which is substantially different from the melting point of Efavirenz and Adipic acid. These results suggested the complete formation of co-crystals of Efavirenz with Lactic acid and Adipic acid and not simple physical mixtures. The co-crystals described here showed large variation in melting temperature from that of Efavirenz, suggesting that the cohesive energy of co crystals A and B is decreased and increased from that of pure drug Efavirenz.

In analysis of the X-ray Powder Diffraction data of the polycrystalline materials arising from solvent evaporation experiments revealed that for critical co-crystal formation of Efavirenz with Lactic acid or Adipic acid, reflections arising from the starting materials are absent, indicating the presence of new phase when they were taken in proportion of 1:5 for co-crystals of Efavirenz with Lactic acid and co-crystals of Efavirenz with Adipic acid. XRPD analysis supports the formation of co crystals of Efavirenz with Lactic acid or Adipic acid as showing different patterns in diffractogram with that of pure Efavirenz (Figure 3A-3C). In SEM results reveals that a pure drug Efavirenz 


\begin{tabular}{|c|c|c|c|c|c|c|c|c|c|c|c|c|}
\hline \multirow[t]{3}{*}{ S. No. } & \multirow[t]{3}{*}{ Time (min) } & \multicolumn{11}{|c|}{$\%$ Cumulative drug release } \\
\hline & & \multirow[t]{2}{*}{ Efavirenz } & \multicolumn{5}{|c|}{ Lactic acid (1:5) } & \multicolumn{5}{|c|}{ Adipic acid (1:5) } \\
\hline & & & 1:1 & 1:2 & $1: 3$ & $1: 4$ & 1:5 & 1:1 & $1: 2$ & $1: 3$ & $1: 4$ & 1:5 \\
\hline 1 & 00 & 00 & 00 & 00 & 00 & 00 & 00 & 00 & 00 & 00 & 00 & 00 \\
\hline 2 & 05 & 26.37 & 04.11 & 05.84 & 06.82 & 10.44 & 35.17 & 10.92 & 13.96 & 18.31 & 18.34 & 24.83 \\
\hline 3 & 10 & 27.86 & 07.68 & 08.81 & 10.29 & 14.48 & 45.37 & 14.37 & 17.48 & 21.11 & 23.98 & 25.30 \\
\hline 4 & 15 & 38.94 & 11.10 & 12.11 & 12.92 & 24.63 & 50.13 & 24.74 & 21.00 & 26.48 & 27.42 & 39.41 \\
\hline 5 & 30 & 58.66 & 13.70 & 14.85 & 17.81 & 35.28 & 65.41 & 28.33 & 31.62 & 42.18 & 46.26 & 50.16 \\
\hline 6 & 45 & 62.50 & 24.07 & 25.21 & 35.22 & 51.67 & 83.66 & 35.25 & 38.05 & 47.02 & 56.00 & 79.41 \\
\hline
\end{tabular}

Table 6: Dissolution studies of Efavirenz co-crystal with Lactic acid or Adipic acid.

\begin{tabular}{|c|c|c|}
\hline \multirow{2}{*}{ Time in $\min$} & \multicolumn{2}{|c|}{ Efavirenz Co crystal tablet with } \\
\cline { 2 - 3 } & Lactic acid (1:5) & Adipic acid (1:5) \\
\hline 05 & 34.70 & 25.20 \\
\hline 10 & 44.90 & 27.41 \\
\hline 30 & 49.95 & 40.97 \\
\hline 45 & 66.10 & 51.50 \\
\hline
\end{tabular}

Table 7: In Vitro drug release of Efavirenz co-crystal tablet (Lactic acid or Adipic acid).

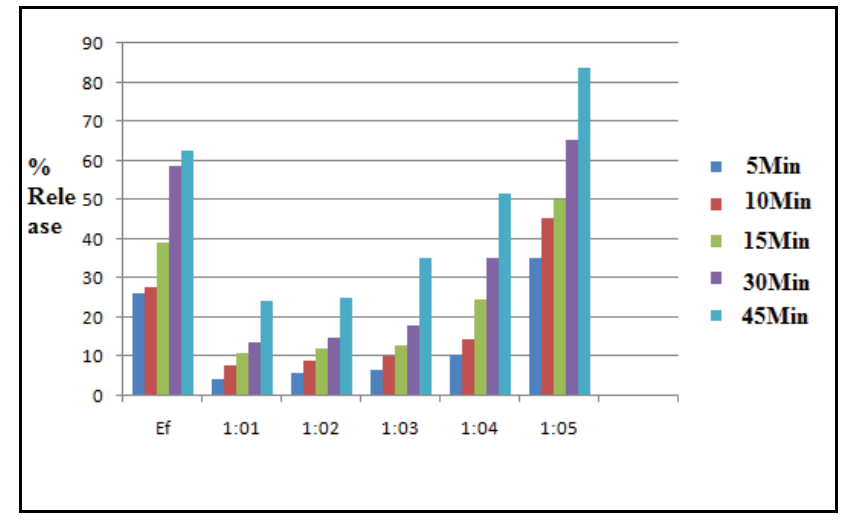

A

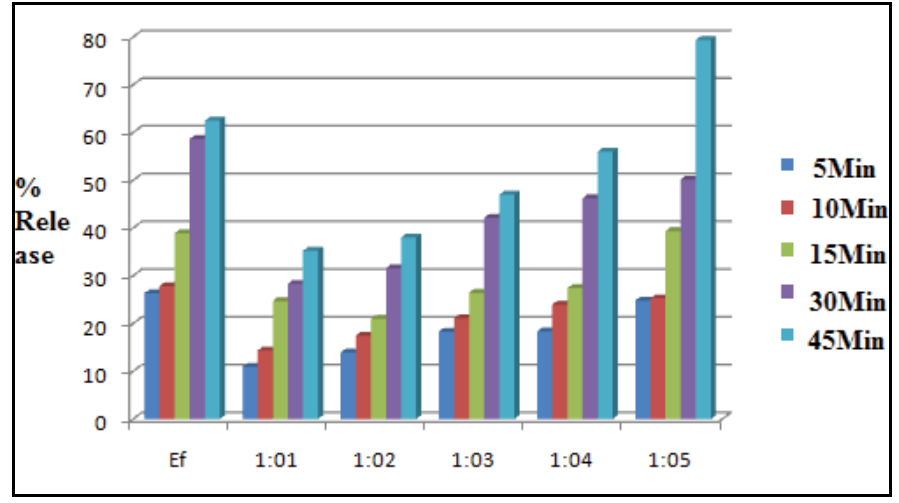

B

Figure 6: In vitro dissolution study of Efavirenz co-crystals with (A) Lactic acid and (B) Adipic acid.

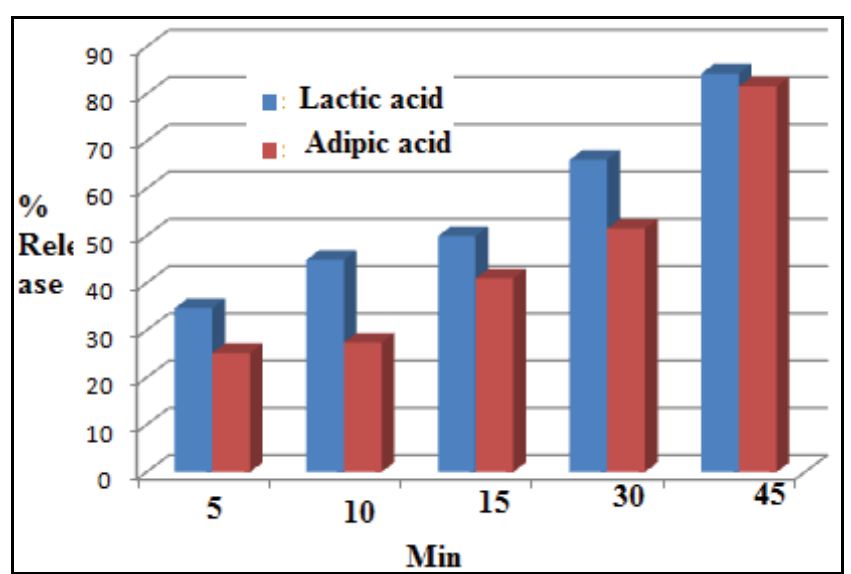

Figure 7: In Vitro drug release of Efavirenz co-crystal tablet (Lactic acid and Adipic acid).

exhibited irregular shape with smooth surface and the co-crystals of Efavirenz with Lactic acid or Adipic acid also exhibited irregular shape but the shape was different with those of the pure drug as shown in Figure 4A-4C. In FT-IR spectroscopy for Efavirenz and its co crystals

\begin{tabular}{|c|c|c|}
\hline Co-crystal & Efficiency & Drug content \\
\hline Lactic acid (1:5) & $3.84 \mathrm{mg}$ & $97.66 \%$ \\
\hline Adipic acid (1:5) & $3.87 \mathrm{mg}$ & $98.29 \%$ \\
\hline
\end{tabular}

Table 8: Efficiency of Efavirenz co-crystals with Lactic acid and Adipic acid.

shows various FT-IR frequency bands are present in spectra's, In Efavirenz co crystals with Lactic acid shows shift in $\mathrm{O}-\mathrm{H}$ bond of Lactic acid to low frequency at $3391 \mathrm{~cm}^{-1}$ from $3395 \mathrm{~cm}^{-1}$ and in case Efavirenz co crystals with Adipic acid shows shift in $\mathrm{O}-\mathrm{H}$ bond of Lactic acid to low frequency at $3390 \mathrm{~cm}^{-1}$ from $3350 \mathrm{~cm}^{-1}$ of which reveals that drug is compatible with co formers as well as formation of co crystals as shown in Figure 5A and 5B. The dissolution curves of pure Efavirenz and its co-crystals with Lactic acid and Adipic acid and there prepared tablet formulation in phosphate buffer $\mathrm{pH} 7.2$ reveals that improvement in release profile in 45 minutes by 33.85 and $27.05 \%$ respectively when compared with pure Efavirenz pure drug (Tables 6 and 7; Figures 6 and 7).

The micromeritics properties like bulk density, tapped density, angle of repose and Carr's index were determined and shown in Tables 2 and 3. The tapped density of the co-crystals of the Efavirenz with Lactic acid and Adipic acid are lower than the corresponding value of the Efavirenz pure drug. The lower density is likely to be related to the intraparticle porosity and almost retained bulk density of the treated samples indicates a greater porosity within the co-crystals of 
Efavirenz with Lactic acid and Adipic acid particles. Carr's index of the co-crystals of Efavirenz with Lactic acid and Adipic acid was found to be lower when compared to Efavirenz pure drug. Fine particles having high surface to mass ratios are more cohesive than coarser particles, hence more influenced by gravitational force. Decreased values of Carr's index for co-crystals of Efavirenz with Lactic acid and Adipic acid indicate better pack ability, and that they might be suitable for direct tableting. Flow properties of the co-crystals of Efavirenz with Lactic acid and Adipic acid were reflected by angle of repose. It was found that angle of repose of the co-crystals of Efavirenz with Lactic acid and Adipic acids were decreased when compared to Efavirenz pure drug. Such decreased value indicates improvement in flow ability. Lower densities of the Efavirenz with Lactic acid and Adipic acid than the Efavirenz pure drug indicate better crystallinity and porosity. Lower Carr's index of the co-crystals of the Efavirenz with Lactic acid and Adipic acid makes their pack ability better, and suitable for direct tableting.

\section{Conclusions}

Synthesis of Efavirenz Co crystals with Lactic acid and Adipic acid were successfully prepared by solvent evaporation method ; aqueous solubility also enhanced by $33.85 \%$ and $27.05 \%$ respectively. Upon formulation and development of co crystals; micromeritics properties are found improved for development of tablet formulation.

\section{Acknowledgements}

The authors thank to Shri. Prashant Patil Gadakh, President, Mula Education Society's, Sonai and Dr. V.K. Deshmukh, Principal, MES College of Pharmacy, Sonai for providing all laboratory facilities, UDCT Dr. BAMU, Aurangabad for recording FT-IR Spectra, Government College of Pharmacy, Aurangabad for recording DSC, Diya Labs, Mumbai for recording XRPD.

\section{References}

1. Ford N, Mofenson L, Shubber Z, Calmy A, Andrieux-Meyer I, et al. (2014) Safety of efavirenz in the first trimester of pregnancy: an updated systematic review and meta-analysis. AIDS 28 Suppl 2: S123-131.

2. Madhusudhan A, Bhagavanth Reddy G, Venkatesham M, Veerabhadram $G$ (2012) Design and Evaluation of Efavirenz loaded Solid Lipid Nanoparticles to Improve the Oral Bioavailability. International Journal of Pharmacy and Pharmaceutical Science Research 2: 84-89.

3. Renu C, Anupam S, Poonam A, Somnath C, Dharamvir singh J (2012) Cocrystals of efavirenz with selected coformers: preparation and Characterization. Int $\mathrm{J}$ Pharm Pharm Sci 4: 244-250.

4. Maleki Dizaj S, VazifehasI Z, Salatin S, Adibkia K, Javadzadeh Y (2015) Nanosizing of drugs: Effect on dissolution rate. Research in Pharmaceutical Sciences 10: 95-108.
5. Zalte AG, Saudagar RB (2014) Advanced Techniques in Preparation of Cocrystals. International journal of scientific progress and research 12: 32-35.

6. Korotkova El, Kratochvl B (2014) Pharmaceutical Cocrystals. Procedia Chemistry 10: 473-476.

7. Vishweshwar P, McMahon JA, Bis JA, Zaworotko MJ (2006) Pharmaceutical co-crystals. J Pharm Sci 95: 499-516.

8. Trask AV, Jones W (2005) Crystal engineering of organic crystals by the solid state grinding approach. Top Curr. Chem 41-70.

9. Berry D, Seaton C, Clegg W, Harrington R, Coles S, et al. (2008) Applying hotstage microscopy to co-crystal screening: a study of nicotinamide with seven active pharmaceutical ingredients. Cryst Growth Des 8: 1697-1712.

10. Basavoju S, Bostrom D, Velaga SP (2008) Indomethacin-saccharin cocrystal: design, synthesis and preliminary pharmaceutical characterization. Pharm Res 25: 530-541.

11. Gaivoronskii AN, Granzhan VA (2005) Solubility of Adipic acid in organic solvent and water. Russian journal of applied chemistry 78: 404-408.

12. Changyan G, Haobin Z, Xiaochuan W, Jinjiang X, Yu L, et al. (2013) Crystal structure and explosive performance of a new CL-20/caprolactam cocrystal. Journal of Molecular Structure 1048: 267-273.

13. Vikas G Rajurkar, Ravikumar D Gite, Vilas B (2015) Ghawate.Development of naproxen co crystal formation: an efficient approach to enhance aqueous solubility. Analytical Chemistry Letters (In Press)

14. Pritish K, Sunil D, Inayat BP, Harsha S (2012) Preparation of spherical crystal agglomerates via crystallo-co-agglomeration technique. Digest journal of nanomaterials and biostructures 7: 1223-1236.

15. Hong-Liang L, Po-Chun H, Shan-Yang L (2013) Theophylline-citric acid cocrystals easily induced by DSC-FTIR microspectroscopy or different storage conditions. Asian journal of pharmaceutical sciences 8: 19-27.

16. Abdolhassan D, Hossein EH, Masoud M, Mohsen N, Fazlara A, et al. (2014) Investigation of regioselectivity on the reaction of 5-bromo-2,4-dichloro-6methylpyrimidine with ammonia. Arabian Journal of Chemistry 7: 1000-1002.

17. Han W, Anthony RW, Martin V, Apperley DC, Alan GJ (2012) Synthesis, crystallization and characterization of diastereomeric salts formed by ephedrine and malic acid in water. Chemical Engineering Science 77: 47-56.

18. Siok-Yee C, Yin-Ying C, Xin-Zi C, Eryn Yen-LT, Joan Q (2015) The characterization and dissolution performances of spray dried solid dispersion of ketoprofen in hydrophilic carrier. Asian Journal of Pharmaceutical Sciences 1-14 (In Press).

19. Neha T, Mohit T, Neha G, Upendra N (2012) Formulation and evaluation of fast disintegrating tablets of caffeine by using effervescent formulation approach. Der Pharmacia Lettre 4: 1490-1494.

20. Prakash K, Jieun R, Hyeongmin K, Iksoo K, Jeong TK, et al. (2014) Pharmaceutical particle technologies: An approach to improve drug solubility, dissolution and bioavailability. Asian journal of pharmaceutical sciences 9: 304-316. 